Research Article

\title{
XRD-Rietveld Method for Evaluating the Leaching Characteristics of Hardened Cement Paste in Flowing Water
}

\author{
Lunchao Zhang, ${ }^{1,2}$ Jikai Zhou $\mathbb{D}^{1}{ }^{1} \mathrm{Xu} \mathrm{He},{ }^{1}$ and Chen Chen ${ }^{1}$ \\ ${ }^{1}$ College of Civil and Transportation Engineering, Hohai University, Nanjing 210098, China \\ ${ }^{2}$ School of Civil Engineering, Chuzhou Vocational and Technical College, Chuzhou 239000, China \\ Correspondence should be addressed to Jikai Zhou; zhoujikaihhu@hotmail.com
}

Received 31 October 2019; Revised 18 March 2020; Accepted 30 July 2020; Published 18 August 2020

Academic Editor: Claudio Mazzotti

Copyright (C) 2020 Lunchao Zhang et al. This is an open access article distributed under the Creative Commons Attribution License, which permits unrestricted use, distribution, and reproduction in any medium, provided the original work is properly cited.

\begin{abstract}
In order to study the leaching characteristics of hardened cement paste by flowing environmental water, indoor simulated leaching tests of Portland cement paste were carried out at different flow velocities with home-made flow field device and tap water as the erosion medium. By means of mechanical properties tests, X-ray diffraction (XRD), and Rietveld full-spectrum quantitative analysis of specimens after leaching at different ages, the change rules of the flexural strength, main phase composition, and mass fraction of the specimens after leaching were obtained. The results show that, within 90 days, the flow rate in the test has no obvious effect on the leaching of hardened cement paste. With the increase in age, the leaching of hardened cement paste gets more obvious. Rietveld full-spectrum quantitative analysis shows that the leaching of hardened cement paste changes with the relative content of $\mathrm{CaCO}_{3}$ and $\mathrm{Ca}(\mathrm{OH})_{2}$. The higher the relative content of $\mathrm{CaCO}_{3}$ is, the better compaction and leaching resistance the paste has. The leaching resistance of hardened cement paste is also related to the gradient of $\mathrm{Ca}(\mathrm{OH})_{2}$. The smaller the gradient is, the better the leaching resistance is. The Rietveld full-spectrum quantitative analysis method can be used as a method to evaluate the leaching effect of hardened cement paste.
\end{abstract}

\section{Introduction}

Concrete structures such as dams, bridges, ports, wharves, and tunnels are vulnerable to erosion by flowing water $[1,2]$, which affects the durability and service life of them $[3,4]$. Calcium ion is the main component of hydration products of Portland cement, and its content affects the stability of hydration products. Flowing water will cause the diffusion and leaching of $\mathrm{Ca}(\mathrm{OH})_{2}$ in concrete and the decalcification of C-S-H gel $[5,6]$. The leaching of calcium ion in concrete is largely responsible for the reduction of concrete strength [7], and the dynamic leaching rate is higher than the static leaching rate.

The leaching test methods include the direct method and indirect method. Direct method is usually used to test the leaching of specimens directly with pure water or deionized water [8]. The indirect method is to use chemical solution to accelerate the test, such as ammonium nitrate solution [9], ammonium chloride solution, and electrochemical theory. [10]. In terms of test efficiency, the leaching process of specimens in the direct method is relatively slow $[11,12]$. The indirect method has the characteristic of fast erosion speed $[13,14]$, but the chemical reaction is complex and there are many influencing factors.

The leaching of concrete is mainly caused by the leaching of hardened cement paste, accompanied by the change in crystal content of hydration products, such as $\mathrm{Ca}(\mathrm{OH})_{2}$, $\mathrm{CaCO}_{3}, \mathrm{C}-\mathrm{S}-\mathrm{H}$, and $\mathrm{SiO}_{2}$. There are many parameters to evaluate the leaching effect, such as the permeability of concrete, the change in $\mathrm{pH}$ value of leachate, the quantity of dissolved chemical substances, and the loss of mass and strength. [15]. XRD can be used to identify and quantify the mineral composition of cement-based materials, discriminate hydration products, study the hydration process of cement, and determine the hydration rate of cement clinker minerals $[9,16]$. The method based on full-spectrum 
structure fitting (Rietveld) can be used to analyze the influence of hydration properties $[17,18]$, phase quantification, and evolution of cement-based materials $[19,20]$ and the influence of pozzolanic action [21, 22]. The standard samples are not required in the method but only the structure information, so it has high accuracy. Actually, there are two kinds of quantitative methods for phase analysis by X-ray diffraction: one is the traditional quantitative method (external standard method and internal standard method); the second method is based on fullspectrum structure fitting (Rietveld diffraction spectrum analysis). The former method requires a standard sample when quantifying. The later, full-spectrum fitting quantitative analysis, has a high accuracy, which only needs to know the structure information of the phase, with no need of the standard sample, and can call the crystal structure information of the phase in the software.

In order to simulate the leaching characteristics of concrete in real-water environment, especially the leaching of hardened cement paste in underground concrete structure by groundwater of reservoir, the ordinary Portland hardened cement paste was taken as the research object and a homemade flow leaching device was used. The mechanical properties, main hydration products composition, and relative mass change in the hardened cement paste specimens leached with different flow rates at different ages were analyzed in order to obtain the leaching characteristics of hardened cement paste under the action of flowing tap water.

\section{Materials and Methods}

2.1. Materials and Mix Proportions. The cement used in the test was ordinary Portland cement (OPC) and superfine cement (SMC) with 5\% silica fume, and the strength grade was 42.5. The physical properties of the materials are shown in Tables 1 and 2. Ultrafine cement was obtained by grinding OPC. Its average particle size was $4.25 \mu \mathrm{m}$, and the specific surface area was $3770 \mathrm{~m}^{2} / \mathrm{kg}$. Tap water was used as mixing water and leaching medium. The $\mathrm{pH}$ value of tap water was 7.5-8.0.

\subsection{Preparation of the Specimens}

2.2.1. Specimens for Leaching and Mechanical Tests. The specimens were prisms of size $10 \mathrm{~mm} \times 10 \mathrm{~mm} \times 60 \mathrm{~mm}$. The water-binder ratio was 0.55 . After the cement paste was molded, the standard curing time was $24 \mathrm{~h}$, and then, the mold was removed and the leaching test was carried out. There were 3 specimens in each group in the flexural strength test. The strength value was taken as the average of the measured values of three specimens.

2.2.2. XRD Testing. Sampling positions were $0-2 \mathrm{~mm}$ (surface), 2-4 mm (middle), and $>4 \mathrm{~mm}$ (core) depth, respectively (shown in Figure 1). The samples were placed in an agate bowl and grinded manually until they passed through 200 meshes $(0.074 \mathrm{~mm})$ sieve, and then, $5 \mathrm{~g}$ samples were randomly taken. In order to prevent carbonization during grinding, anhydrous ethanol was added to the grinder. The samples were dried to constant weight at $40^{\circ} \mathrm{C}$ in the oven, and then, the XRD spectra were collected in $\mathrm{X}$-ray diffractometer.

2.3. Tests and Methods. After 24-hour standard curing, the specimens were dismantled and soaked in water tanks, respectively. The experimental flow velocities were $0 \mathrm{~mm} / \mathrm{s}$, $2.8 \mathrm{~mm} / \mathrm{s}$, and $11.2 \mathrm{~mm} / \mathrm{s}$, respectively. The experimental flow velocities were calculated according to the groundwater flow field of a reservoir project. The actual average flow velocity was $2.8 \mathrm{~mm} / \mathrm{s}$ and $0 \mathrm{~mm} / \mathrm{s}$ meant that groundwater did not flow. The test ages were $3 \mathrm{~d}, 7 \mathrm{~d}, 28 \mathrm{~d}, 56 \mathrm{~d}$, and $90 \mathrm{~d}$, respectively.

As shown in Figure 2, the flow field test device consisted of an upper water tank, a lower water tank, a flow control valve, a flow tank, a support platform for the upper water tank, a support platform for the flow tank, a sand cushion, a water pump, and a water pipe. After the water in the upper tank flowed out from the flow control valve, it entered the flume to erode the specimens on the sand cushion. There was an opening at the end of the flume. The water flowed out from the opening and entered the lower tank. The upper water tank was a high-strength plastic water tank with a capacity of $200 \mathrm{~L}$. The water in the tank was controlled intelligently to maintain a uniform height. The flow tank was a PVC rectangular tank with a net width of $92 \mathrm{~mm}$. Six specimens could be arranged evenly along the width direction. The specific operation steps were as follows:

(1) Appropriate amount of water was injected into the upper water tank, and then, the flow control valve was opened; the flow rate was calibrated by measuring cylinder and stopwatch, and the opening degree of the valve was adjusted.

(2) The test blocks were put into the flow tank, and a gap was kept between the test blocks for the flow to pass through, while a part of the test blocks was reserved for curing in still water under the same conditions.

(3) When reaching the required erosion time, the specimens were tested for flexural strength and XRD. Six specimens in each group were tested, of which three were for flexural strength, and the other three for XRD. The testing age of XRD was $28 \mathrm{~d}, 56 \mathrm{~d}$, and $90 \mathrm{~d}$. Among them, the $56 \mathrm{~d}$ samples were also tested for XRD with different depths.

2.3.1. Leaching Resistance Coefficient Tests. The ratio of the flexural strength of specimens leached with different flow rates to that of hydrostatically leached specimens at the same age was defined as the leaching resistance coefficient, and the leaching resistance coefficient was used to evaluate the leaching effect of cement-based materials. The larger the coefficient was, the better the leaching resistance of the material was. The flexural strength of the specimens was tested by three-point bending-tension test, and $L$ was $40 \mathrm{~mm}$ : 
TABLE 1: Physical properties of OPC.

\begin{tabular}{lcccccccc}
\hline Analysis item & $\mathrm{CaO}(\%)$ & $\mathrm{SiO}_{2}(\%)$ & $\mathrm{Al}_{2} \mathrm{O}_{3}(\%)$ & $\mathrm{Fe}_{2} \mathrm{O}_{3}(\%)$ & $\mathrm{MgO}(\%)$ & $\mathrm{SO}_{3}(\%)$ & $\mathrm{Na}_{2} \mathrm{O}+\mathrm{K}_{2} \mathrm{O}(\%)$ & $\mathrm{LOI}(\%)$ \\
\hline OPC & 55.72 & 23.42 & 7.64 & 2.93 & 3.15 & 2.41 & 0.41 & 2.7 \\
\hline
\end{tabular}

TABle 2: Physical properties of silica fume.

\begin{tabular}{lccccccccc}
\hline $\begin{array}{l}\text { Analysis } \\
\text { item }\end{array}$ & $\mathrm{SiO}_{2}(\%)$ & $\mathrm{Na}_{2} \mathrm{O}(\%)$ & $\mathrm{K}_{2} \mathrm{O}(\%)$ & $\mathrm{R}_{2} \mathrm{O}(\%)$ & $\mathrm{Cl}^{-}(\%)$ & LOI (\%) & $\begin{array}{c}\text { Activity index } \\
(\%)\end{array}$ & $\begin{array}{c}\text { Specific surface area } \\
\left(\mathrm{m}^{2} / \mathrm{kg}\right)\end{array}$ & $\begin{array}{c}\text { Average particle size } \\
(\mu \mathrm{m})\end{array}$ \\
\hline Silica fume & 93.1 & 0.32 & 0.46 & 0.48 & 0.02 & 2.9 & 107 & 18954 & 0.24 \\
\hline
\end{tabular}

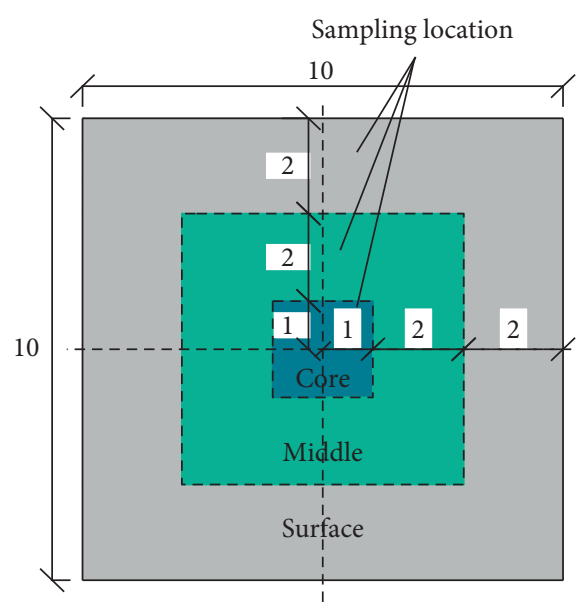

(a)

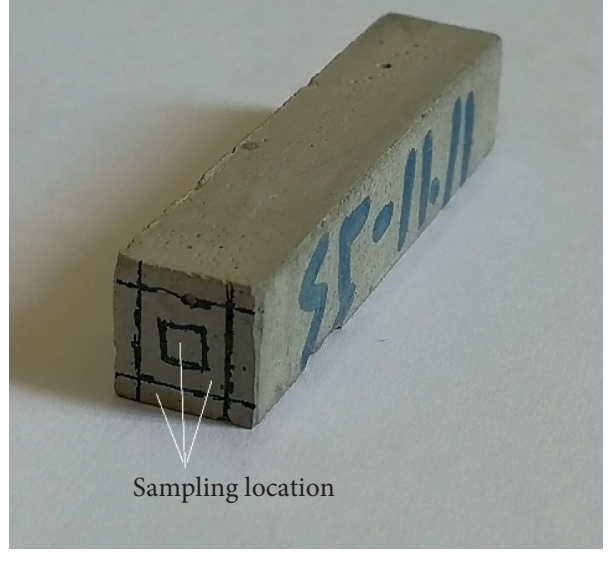

(b)

FIGURE 1: Diagram of sampling position of XRD sample: (a) sampling position of cross section (unit: mm); (b) sample of hardened cement paste and XRD sampling location.

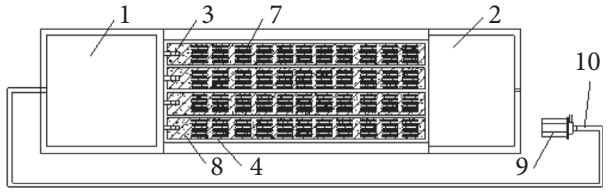

(a)

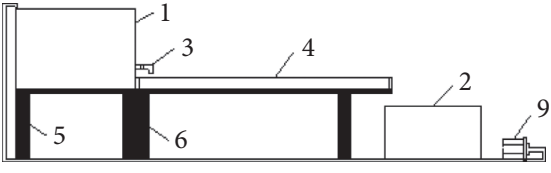

(b)

Figure 2: Schematic diagram of the flowing water erosion test device: (a) vertical view; (b) lateral view (1, upper water tank; 2 , lower water tank; 3, water flow control valve; 4, water channel; 5, upper water tank support platform; 6, water channel support platform; 7, specimen; 8, sand cushion; 9, water pump; 10, water pipe).

$$
K_{f}=\frac{f_{e}}{f_{0}}
$$

where $K_{f}$ is the leaching resistance coefficient; $f_{e}$ is the flexural strength of the test piece under flowing water erosion, $\mathrm{MPa}$; and $f_{0}$ is the flexural strength of the test piece under static water, $\mathrm{MPa}$.

2.3.2. X-Ray Powder Diffraction (XRD). When the multiphase system is irradiated by monochrome X-ray, the diffraction patterns of each phase in the diffraction space superimpose each other to form a one-dimensional diffraction pattern. In the process of weighted overlapping addition of powder diffraction spectra of each phase, the positions of the diffraction lines of each phase will not change, and the intensity of the diffraction lines varies with the percentage of the phase in the mixture (volume or mass), the scattering force, and the absorption force of other phases, and the scale factor is the reflection of the intensity change.

The obtained dry hydration samples were subjected to $\mathrm{X}$-ray diffraction (XRD) analysis using a X-ray diffractometer (D8 ADVANCE, Bruker AXS Corporation, GER) employing $\mathrm{Cu}-\mathrm{K} \alpha$ radiation $(\lambda=0.15418 \mathrm{~nm}, 40 \mathrm{kV}, 50 \mathrm{~mA})$ over scanning range $2 \theta=15^{\circ} \sim 65^{\circ}$ at step width $2^{\circ}$ per min.

\section{Results and Discussion}

3.1. Calculation and Analysis of Leaching Resistance Coefficient. The leaching and decomposition of hydration products occurred after the hardened cement paste was eroded by flowing water, which resulted in the pore structure becoming loose and compactness decreasing and ultimately 

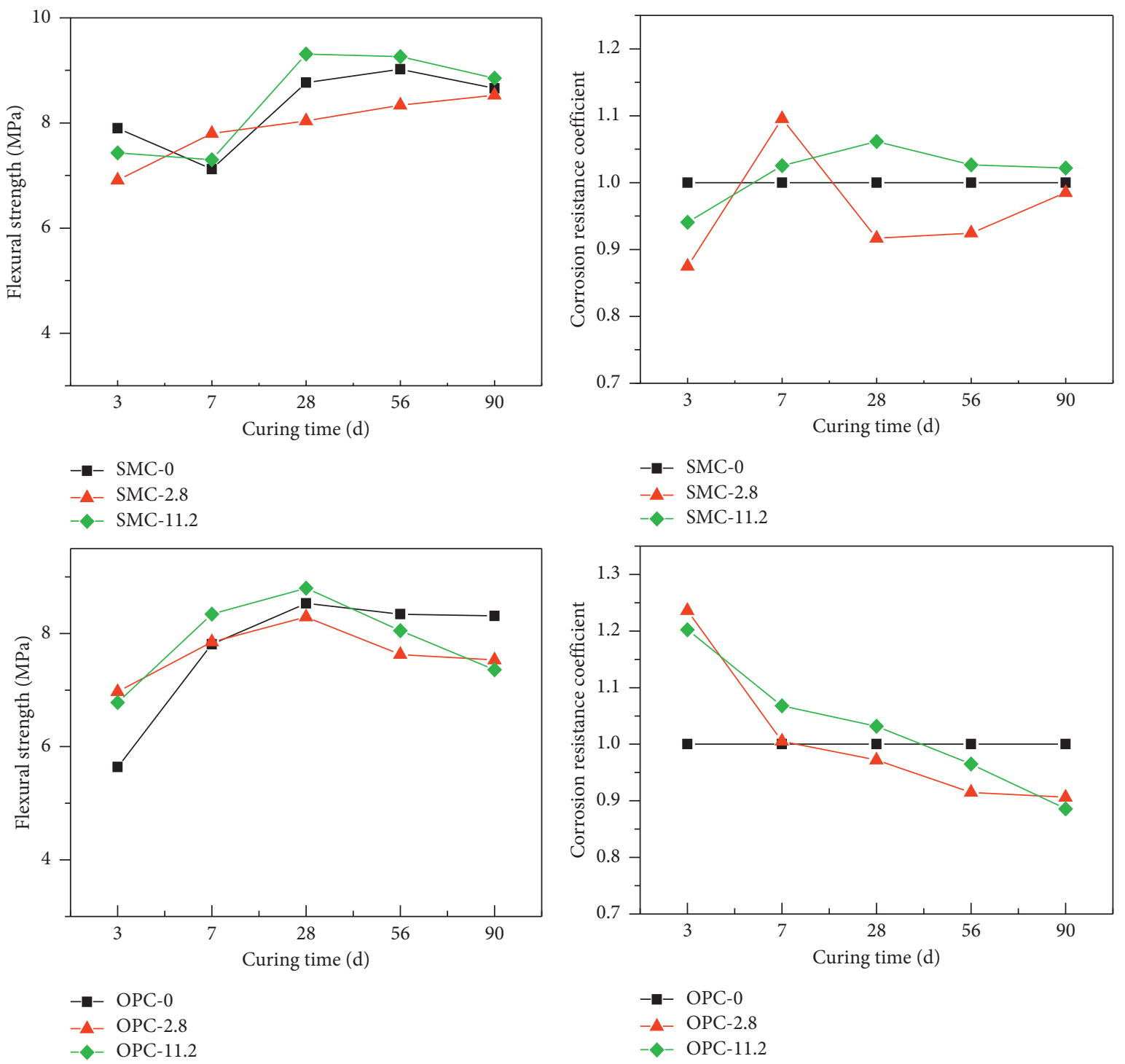

(a)

(b)

FiguRE 3: Mechanical properties of leaching specimens at different ages and flow rates: (a) flexural strength; (b) leaching resistance coefficient.

the mechanical properties deteriorating $[7,23]$. The threepoint flexural tensile strength of specimens at different ages and velocities was tested. The flexural strength is shown in Figure 3(a), and the results of calculation of leaching resistance coefficient by formula (1) are shown in Figure 3(b).

From Figure 3(a), it can be seen that the flexural strength of the specimens increased with the increase in age, the growth rate was relatively high before 28 days, and the OPC is more obvious. The flexural strength of OPC decreased slightly after 28 days, and the decrease in flexural strength of OPC was more obvious than that of SMC. As can be seen from Figure 3(b), the leaching resistance coefficient of OPC decreased gradually, and the boundary point was about 28 days later. The leaching resistance coefficient of SMC increased and approached 1 with the increase in time. The designed flow rate had little effect on the flexural strength within 90 days.
From the change in flexural strength, the leaching resistance of SMC was better than that of OPC. This was related to the addition of silica fume. Active $\mathrm{SiO}_{2}$ in silica fume could produce pozzolanic reaction and filling effect. Free $\mathrm{Ca}(\mathrm{OH})_{2}$ from cement hydration reacted with active $\mathrm{SiO}_{2}$ to form stable low alkalinity C-S-H gel. The C-S-H gel with low alkalinity was more compact and denser than that without silica fume, and its porosity was lower. Its strength was higher than that of $\mathrm{Ca}(\mathrm{OH})_{2}$ crystal. Therefore, the addition of silica fume reduced the content of $\mathrm{Ca}(\mathrm{OH})_{2}$ in the paste, and the macropore was replaced by the small pore, which reduced the most probable pore size and specific surface area, reduced the porosity, and improved the compactness of the structure. Macroscopically, the strength, impermeability, and frost resistance of cement with the addition of silica fume were improved [24]. 



(a)

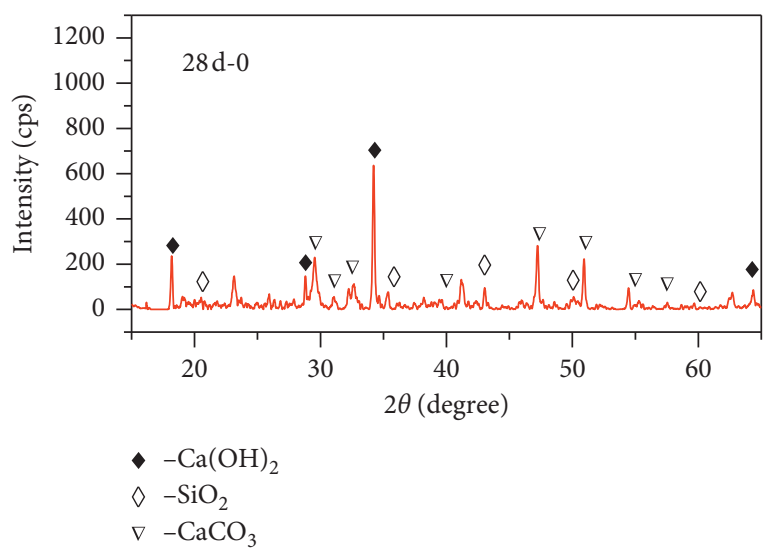

(b)

FIGURE 4: XRD of $28 \mathrm{~d}$ leaching of specimens at different flow rates: (a) OPC; (b) SMC.

3.2. Analysis of XRD-Rietveld. Hydration of Portland cement mainly generates $\mathrm{Ca}(\mathrm{OH})_{2}$ and $\mathrm{C}-\mathrm{S}-\mathrm{H}$, as follows:

$2\left(3 \mathrm{CaO} \cdot \mathrm{SiO}_{2}\right)+6 \mathrm{H}_{2} \mathrm{O} \longrightarrow 3 \mathrm{CaO} \cdot 2 \mathrm{SiO}_{2} \cdot 3 \mathrm{H}_{2} \mathrm{O}+3 \mathrm{Ca}(\mathrm{OH})_{2}$

However, in the water environment, $\mathrm{Ca}(\mathrm{OH})_{2}$ in the hardened cement slurry will interact with $\mathrm{CO}_{2}$ in the air to form $\mathrm{CaCO}_{3}$, as shown in the following equations:

$$
\begin{gathered}
\mathrm{Ca}(\mathrm{OH})_{2}+\mathrm{Ca}\left(\mathrm{HCO}_{3}\right)_{2} \longrightarrow \mathrm{CaCO}_{3}+\mathrm{H}_{2} \mathrm{O} \\
\mathrm{CO}_{2}+\mathrm{H}_{2} \mathrm{O}+\mathrm{Ca}(\mathrm{OH})_{2} \longrightarrow \mathrm{CaCO}_{3}+2 \mathrm{H}_{2} \mathrm{O} \\
\mathrm{CO}_{2}+\mathrm{H}_{2} \mathrm{O}+\mathrm{CaCO}_{3}=\mathrm{Ca}\left(\mathrm{HCO}_{3}\right)_{2}
\end{gathered}
$$

In addition, after the hydration reaction of cement, the relative concentration of hydration product reaches a certain value and keeps an equilibrium. Among them, $\mathrm{Ca}(\mathrm{OH})_{2}$ has the highest limit concentration and is most easily dissolved by permeable water. Once the equilibrium is broken, the amount of $\mathrm{Ca}(\mathrm{OH})_{2}$ will be adjusted, resulting in calcium ion precipitation. So, like the solution is continuously diluted, the hardened cement paste constantly dissolves out calcium hydroxide under the action of current, which can lead to the decalcification of hydrated calcium silicate and the decomposition of $\mathrm{Ca} / \mathrm{Si}$ after lowering. The strength of hardened cement paste reduces, and its performance deteriorates.

3.2.1. XRD Testing. In order to further analyze the leaching characteristics of SMC and OPC from the microscopic scale, $\mathrm{XRD}$ analysis was carried out on the samples. The intensity of XRD diffraction line varied with the percentage (volume or mass) of phase in the mixture, the scattering force, and the absorptive force of the phase. The variation trend reflected the content of the phase.

The main hydration products of ordinary Portland cement are calcium hydroxide (about 20\%), C-S-H gel (about 

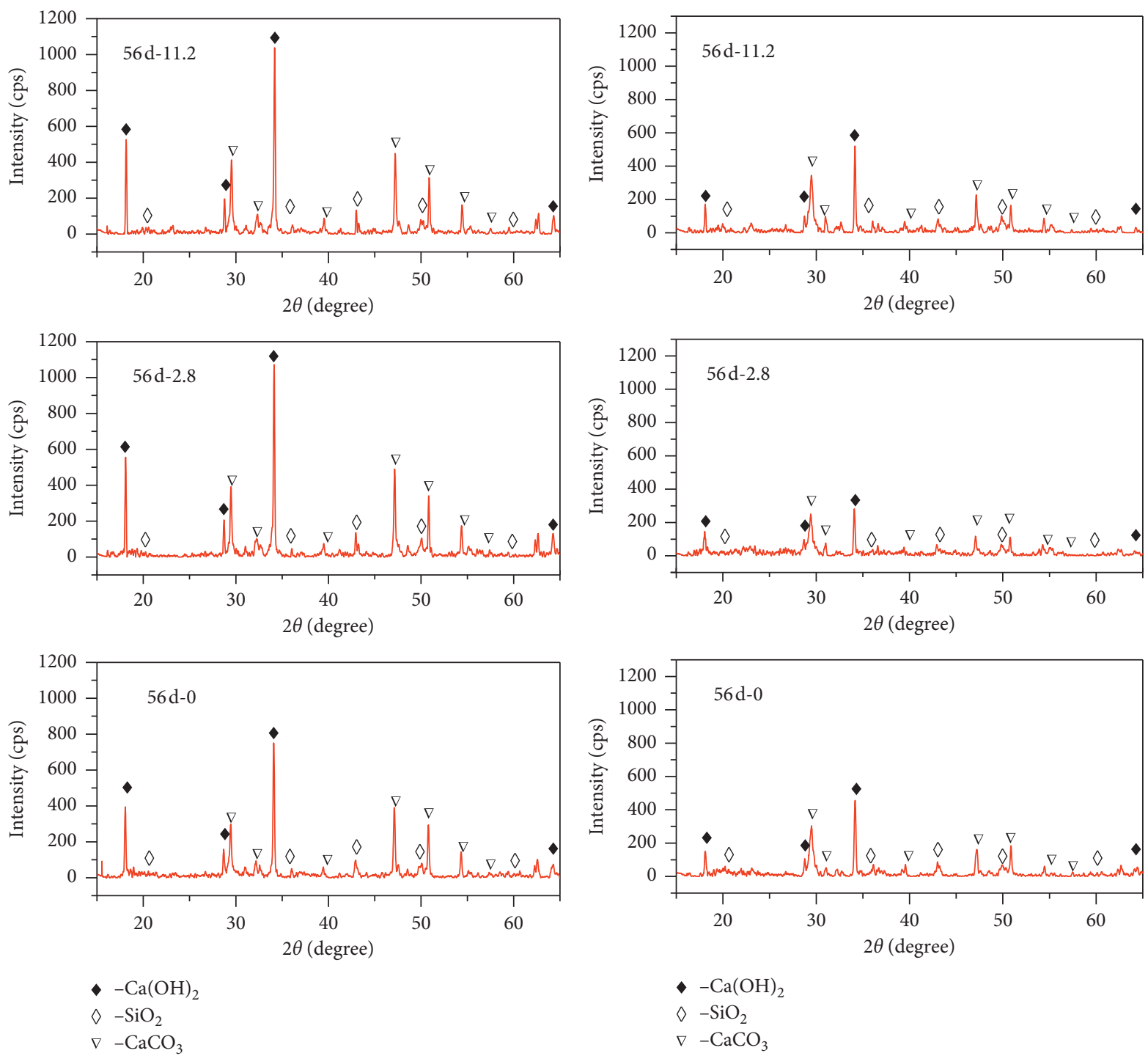

(a)

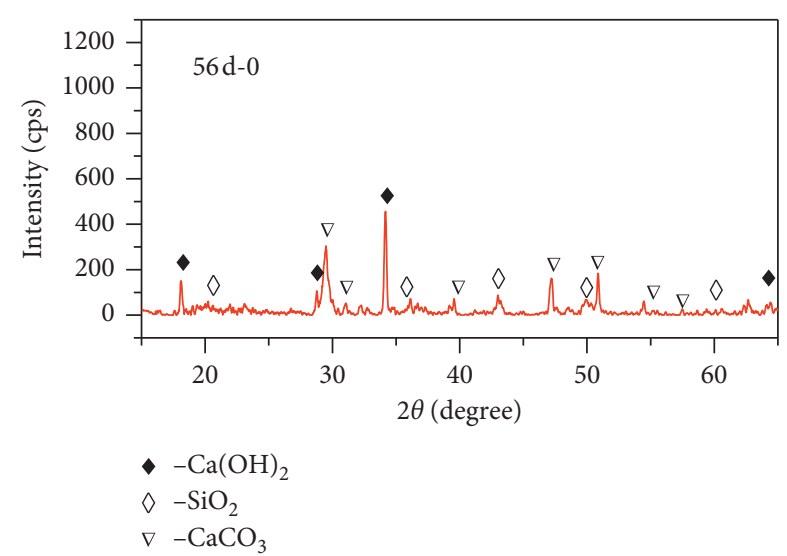

(b)

FIGURE 5: XRD of $56 \mathrm{~d}$ leaching of specimens at different flow rates: (a) OPC; (b) SMC.

$70 \%$ ), calcium sulphoaluminate hydrate (about 7\%), calcium aluminate hydrate, and calcium ferrite hydrate $(<3 \%)[25]$. $\mathrm{C}-\mathrm{S}-\mathrm{H}$ gel was amorphous colloid with poor crystallinity, so $\mathrm{Ca}(\mathrm{OH})_{2}, \mathrm{CaCO}_{3}$, and $\mathrm{SiO}_{2}$ crystals were mainly selected for analysis.

The XRD results of the powder samples sampled at the depth of $0-2 \mathrm{~mm}$ at different ages and velocities are shown in Figures 4-6. XRD results of $56 \mathrm{~d}$ samples with different sampling depths are shown in Figure 7.

Figure 4 shows that $\mathrm{Ca}(\mathrm{OH})_{2}$ was the hydrated product of each sample at $28 \mathrm{~d}$, and its diffraction peak was the highest. In addition, the diffraction characteristic peaks of $\mathrm{CaCO}_{3}$ and $\mathrm{SiO}_{2}$ can be seen, and the diffraction peaks of $\mathrm{SiO}_{2}$ were weak. From Figure 4(a), it can be seen that the diffraction peak of $\mathrm{Ca}(\mathrm{OH})_{2}$ and $\mathrm{CaCO}_{3}$ on the surface of OPC increased with the increase in water velocity. From Figure 4(b), it can be seen that the $\mathrm{Ca}(\mathrm{OH})_{2}$ diffraction peak of SMC decreased with the increase in water velocity, which indicates that less and less $\mathrm{Ca}$ ions can be leached. The diffraction peaks of $\mathrm{CaCO}_{3}$ increased gradually, indicating that more and more stable $\mathrm{CaCO}_{3}$ was formed by calcium ions.

As the curing age increased to $56 \mathrm{~d}$, it can be seen from Figure 5 that the diffraction peaks of $\mathrm{Ca}(\mathrm{OH})_{2}$ and $\mathrm{CaCO}_{3}$ in OPC increased with the increase in flow rate. SMC specimens were the opposite. The diffraction peaks of $\mathrm{SiO}_{2}$ in the samples were still weak, and there was little difference among the samples at different flow velocities.

When the age reached 90 days, the diffraction peaks of $\mathrm{Ca}(\mathrm{OH})_{2}$ and $\mathrm{CaCO}_{3}$ in the sample atlas decreased with the increase in flow rate, which indicates that the leaching of calcium ions tends to be stable and slow. The diffraction peak of $\mathrm{SiO}_{2}$ was still weak.

According to the effect of flow rate on leaching in Figures 4-6, the effect of flow rate set in this experiment on erosion was not obvious. With the increase in age, the effect 

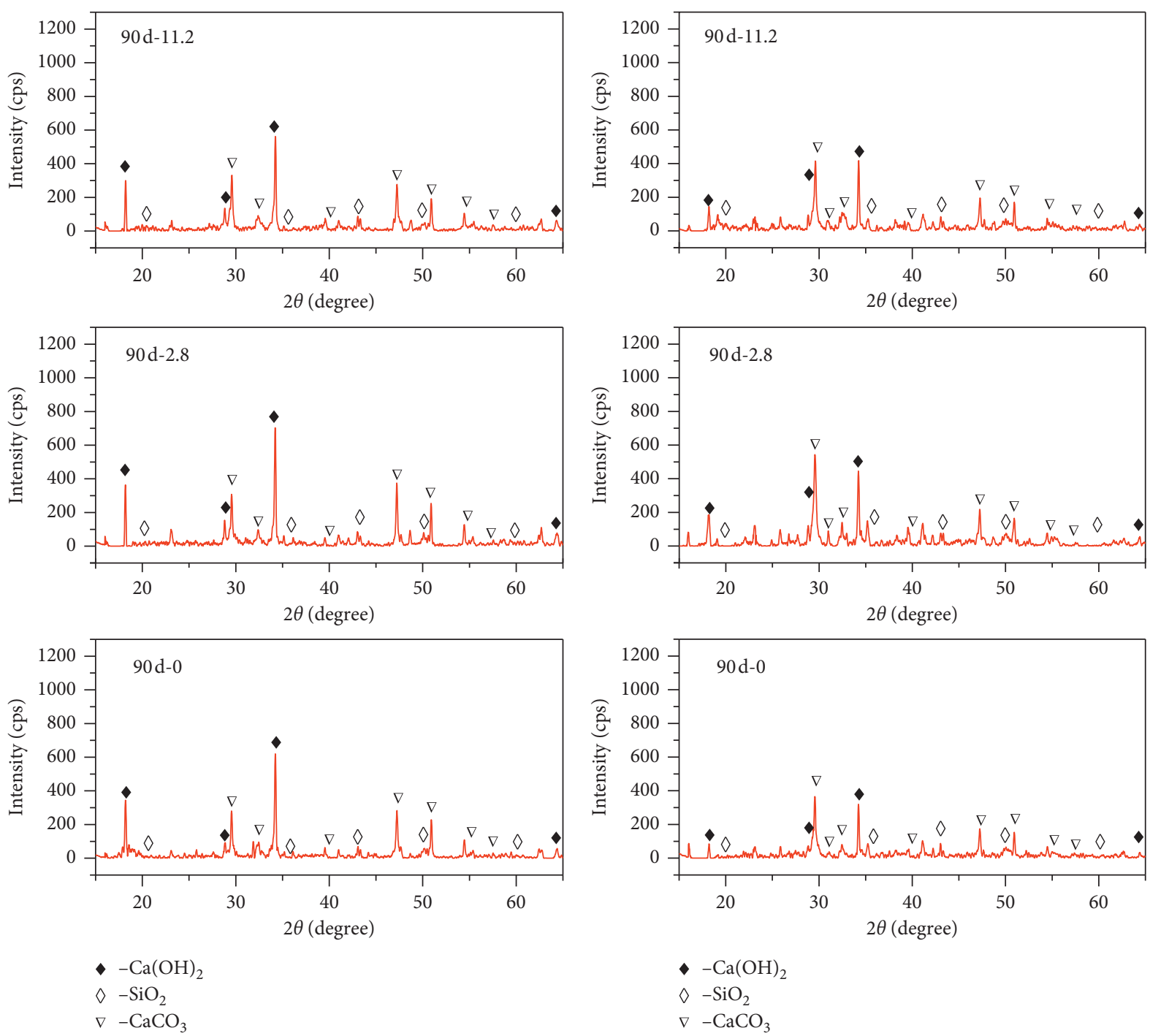

(a)

(b)

FIGURE 6: XRD of $90 \mathrm{~d}$ leaching of specimens at different flow rates: (a) OPC; (b) SMC.

of flow velocity was greater, which indicates that, in the actual environment, the calcium leaching of concrete structure is also a slow process, and the longer the leaching time is, the more obvious the calcium leaching is. The diffraction peaks of $\mathrm{Ca}(\mathrm{OH})_{2}$ and $\mathrm{CaCO}_{3}$ in each sample increased first and then decreased gradually, indicating that the leaching of calcium ions was more before 56 days. The leaching of the specimens proceeded from the surface to the interior gradually. With the increase in the leaching depth, the diffusion and leaching rate of calcium ions slowed down. When the SMC sample was mixed with silica fume, the diffraction peak of $\mathrm{SiO}_{2}$ had little change compared with that of OPC. The main component of silica fume was active $\mathrm{SiO}_{2}$, which had a pozzolanic reaction with cement hydrates, but it was consumed because of its small amount [26]. The decrease in $\mathrm{Ca}(\mathrm{OH})_{2}$ diffraction peak in SMC should be attributed to the reaction with $\mathrm{SiO}_{2}$, and the conversion of hydration products to low alkaline hydration products was also the main reason for the leaching resistance of hardened cement paste with silica fume.

On the one hand, the increase in the diffraction peak of $\mathrm{CaCO}_{3}$ indicates that $\mathrm{Ca}(\mathrm{OH})_{2}$ dissolved into $\mathrm{CaCO}_{3}$ gradually, while $\mathrm{CaCO}_{3}$ was more stable and filled the pore; on the other hand, it would be beneficial to reduce the leaching of $\mathrm{Ca}$ ions. The leaching rate was related to the porosity of hardened cement paste. Combined with the change rule of flexural strength of specimens, this phenomenon was verified. The porosity of ordinary Portland cement paste was larger than that of superfine cement. So OPC was easier to erode than SMC.

$\mathrm{XRD}$ at different sampling depths for $56 \mathrm{~d}$ is shown in Figure 7. The diffraction peak values of $\mathrm{Ca}(\mathrm{OH})_{2}$ and $\mathrm{CaCO}_{3}$ of OPC increased with the depth of sampling. It shows that the leaching of hardened cement paste starts from the surface and deepens gradually. From the point of view of flow rate, the intensity of diffraction peaks of each sample 



- $\mathrm{Ca}(\mathrm{OH})_{2}$

$\diamond-\mathrm{SiO}_{2}$

- $-\mathrm{Ca}(\mathrm{OH})_{2}$

$\diamond-\mathrm{SiO}_{2}$

$\nabla-\mathrm{CaCO}_{3}$

$\nabla-\mathrm{CaCO}_{3}$

- $-\mathrm{Ca}(\mathrm{OH})_{2}$

$\diamond-\mathrm{SiO}_{2}$

$\nabla-\mathrm{CaCO}_{3}$

(a)
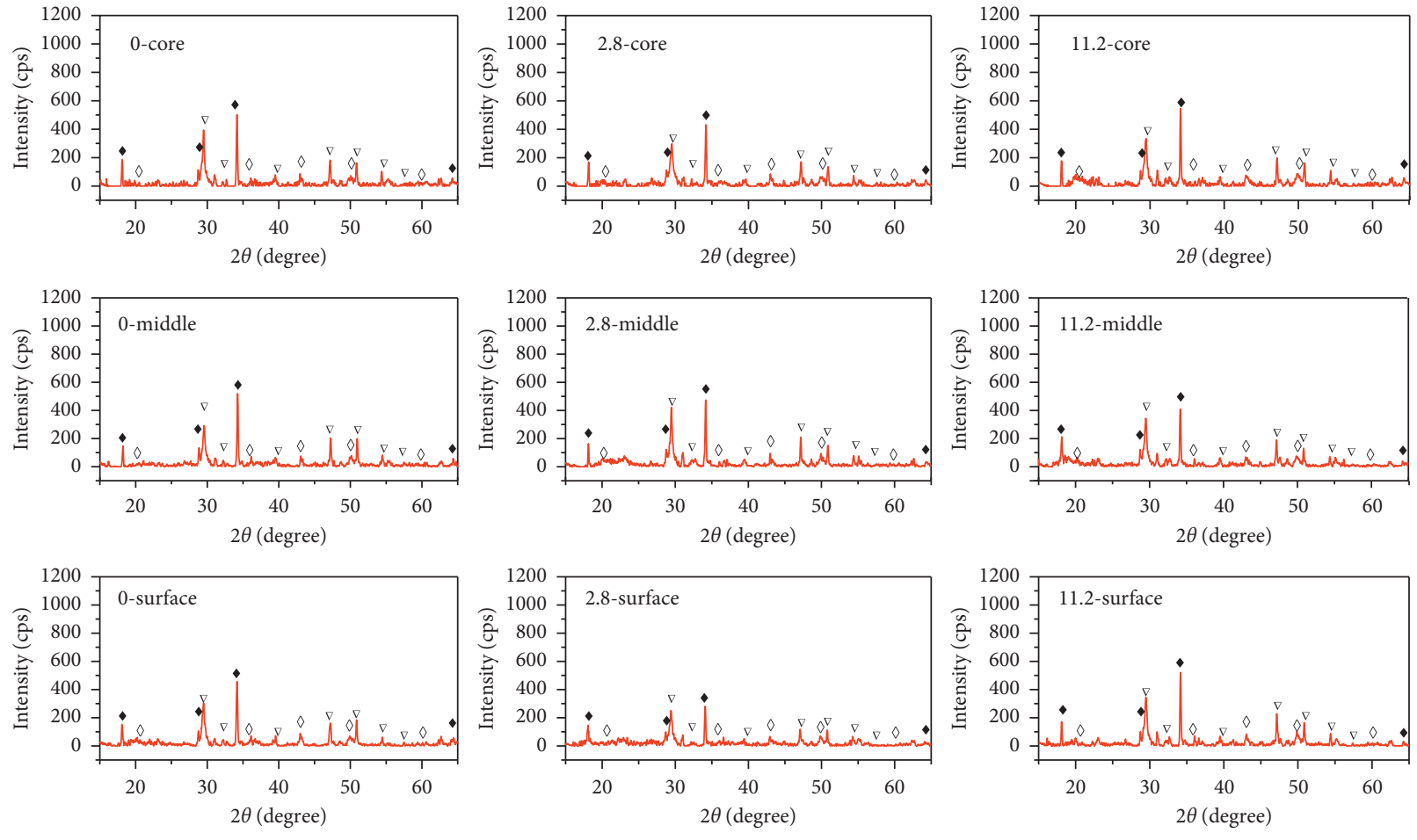

- $-\mathrm{Ca}(\mathrm{OH})_{2}$

- $-\mathrm{Ca}(\mathrm{OH})_{2}$

$\diamond-\mathrm{SiO}_{2}$

- $-\mathrm{Ca}(\mathrm{OH})_{2}$

$\diamond-\mathrm{SiO}_{2}$

$\nabla-\mathrm{CaCO}_{3}$

$\diamond-\mathrm{SiO}_{2}$

$\nabla-\mathrm{CaCO}_{3}$

(b)

FIgURE 7: XRD at different sampling depths for 56 d. 0, 2.8, and 11.2 represent the flow velocity, respectively. (a) OPC; (b) SMC. 


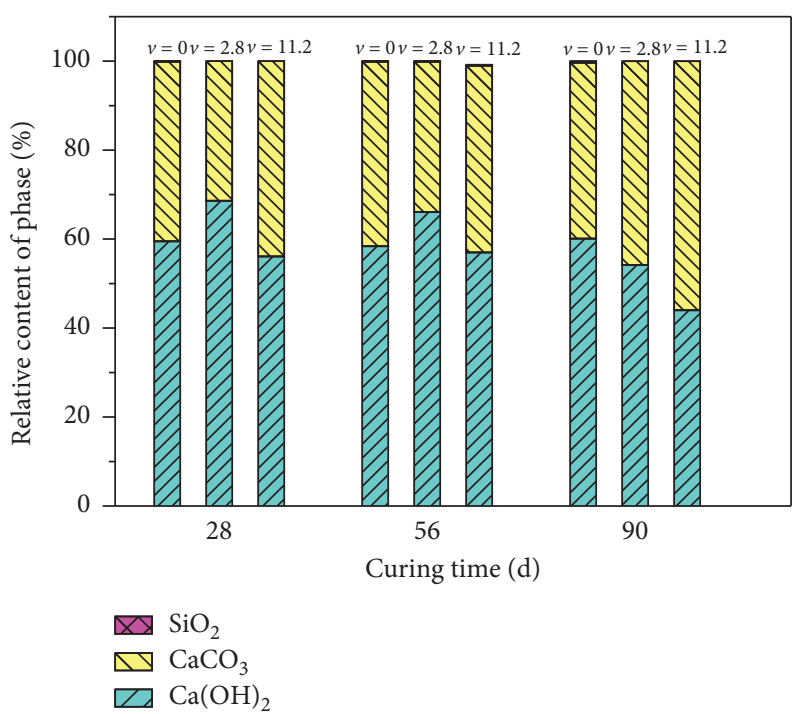

(a)

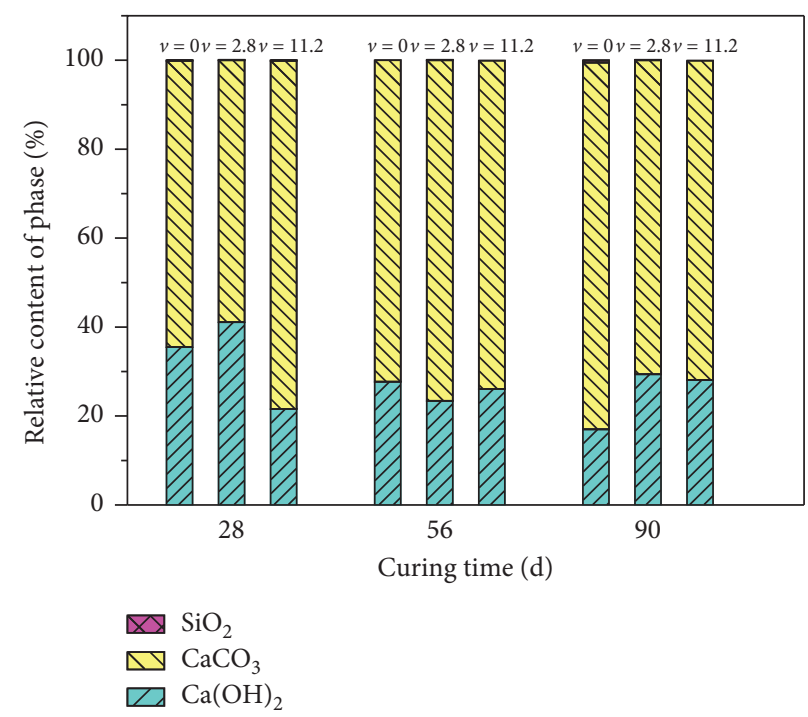

(b)

FIGURE 8: Quantitative analysis of phase mass fraction by XRD-Rietveld for specimens of different ages: (a) OPC; (b) SMC.

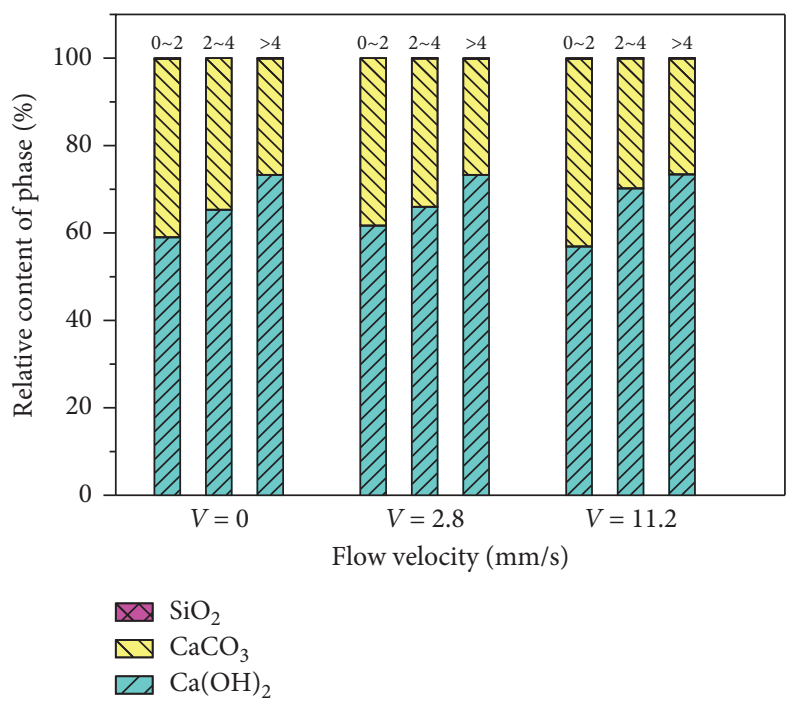

(a)

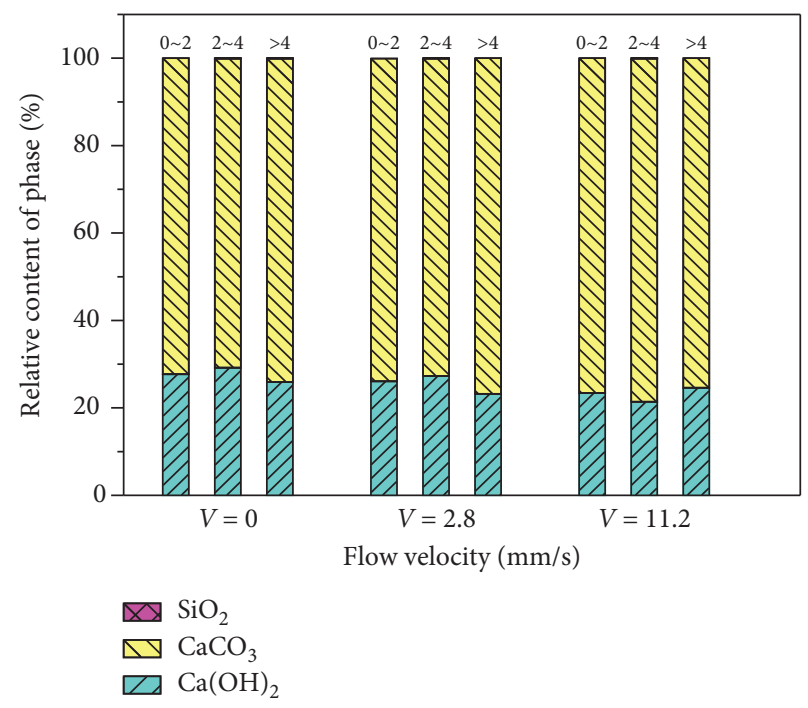

(b)

FIGURE 9: Mass fraction of phase for XRD-Rietveld quantitative analysis of $56 \mathrm{~d}$ samples at different depths: (a) OPC; (b) SMC.

had little change, so the effect of flow rate on leaching was not significant. The intensity of phase diffraction peak of SMC varied little at different depths, which indicates that SMC has good leaching resistance.

3.2.2. Rietveld Quantitative Analysis. From Figures 4 7, it is not easy to quantify and compare the mass change laws of the main phases. Rietveld quantitative phase analysis is based on the relationship between the scaling factor and the reference intensity ratio to obtain the relationship between the relative content of the phase and the scaling factor [27, 28]. Quantitative calculation of phase was carried out by the Rietveld refinement method with Jade software. Quantitative analysis of the phases of different age samples is shown in Figures 8 and 9 .

According to Figure 8(a), the relative mass fractions of $\mathrm{Ca}(\mathrm{OH})_{2}$ and $\mathrm{CaCO}_{3}$ in different depths of OPC specimens changed little with the increase in age, which indicates that the effect of flow rate set in the experiment on calcium leaching was not obvious. However, on the $90^{\text {th }}$ day, the larger the flow rate was, the smaller the amount of $\mathrm{Ca}(\mathrm{OH})_{2}$ was, which indicates that more $\mathrm{Ca}$ ions leached or transformed into $\mathrm{CaCO}_{3}$, and the leaching phenomenon was more obvious. Figure 8(b) shows that, with the increase in age, the relative mass fraction of $\mathrm{Ca}(\mathrm{OH})_{2}$ decreased gradually, while the relative mass fraction of $\mathrm{CaCO}_{3}$ increased gradually, but the change was not obvious. This 

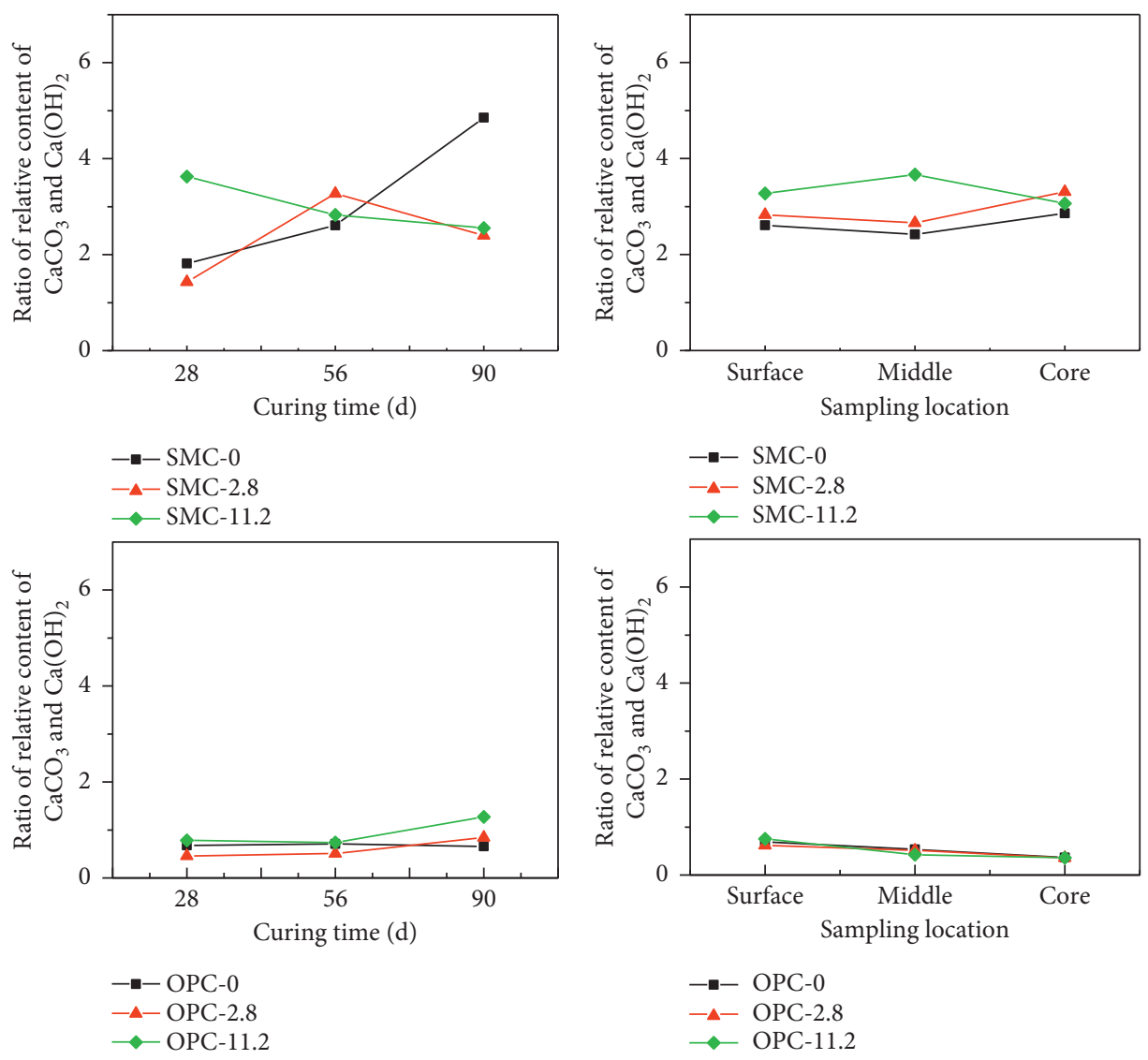

(a)

(b)

FIGURE 10: Change in trend of relative mass ratio of calcium carbonate to calcium hydroxide after leaching: (a) different ages and velocities; (b) different sampling depths at $56 \mathrm{~d}$.

indicates that the reaction between active $\mathrm{SiO}_{2}$ and $\mathrm{Ca}(\mathrm{OH})_{2}$ in silica fume was basically completed on the $28^{\text {th }}$ day. This is consistent with the conclusions of the literature [29, 30]. With the increase in day, the leaching of calcium ions gradually slows down. This is related to $\mathrm{CaCO}_{3}$ filling pore and reducing calcium ion diffusion.

For 56 days of OPC, the relative mass fraction of $\mathrm{Ca}(\mathrm{OH})_{2}$ and $\mathrm{CaCO}_{3}$ was not affected by flow rate. With the increase in sampling depth, the relative mass of $\mathrm{Ca}(\mathrm{OH})_{2}$ increased gradually, while the relative mass of $\mathrm{CaCO}_{3}$ decreased gradually, as shown in Figure 9(a). This indicates that the calcium leaching of OPC was gradual from outside to inside. Figure 9(b) shows that the relative mass fractions of $\mathrm{Ca}(\mathrm{OH})_{2}$ and $\mathrm{CaCO}_{3}$ were not affected by the flow rate and sampling depth of SMC at $56 \mathrm{~d}$. The reaction between active $\mathrm{SiO}_{2}$ and $\mathrm{Ca}(\mathrm{OH})_{2}$ in silica fume was basically completed before 56 days. SMC promoted the hydration of $\mathrm{C}_{3} \mathrm{~S}$ due to the reduction of $\mathrm{Ca}^{2+}$ and $\mathrm{OH}^{-}$concentration in the early stage of cement-water system, shortening the induction period. Fine silica fume particles also acted as crystallization nucleus of hydration products, thus accelerating the early hydration of cement and making the concrete with silica fume have early strength. This is consistent with the results of flexural strength of SMC mentioned above. In addition, due to the pozzolanic reaction,
$\mathrm{Ca}(\mathrm{OH})_{2}$ in cement paste was absorbed with a large amount, forming a low alkalinity C-S-H gel. The amount of $\mathrm{Ca}(\mathrm{OH})_{2}$ decreased with the increase in silica fume and hydration age. From Figures 8 and 9, it can be seen that the relative content of $\mathrm{SiO}_{2}$ in OPC and SMC was very small.

In fact, in running water environment, the calcium dissolution of hardened cement paste occurs at the same time with the hydration of the cement. After 28 days, the hydration rate of the cement slows down, and the dissolution is related to the ion concentration of the solution of the pore. As shown in Figure 3(a), the bending performance of hardened cement paste shows a decreasing trend at different ages and flow rates. From the perspective of XRD, the phase $\mathrm{Ca}(\mathrm{OH})_{2}$ decreases and $\mathrm{CaCO}_{3}$ increases, as shown in Figure 8, which is more obvious at different sampling depths, as shown in Figure 9(a). According to equations (2) (5), as the age increases, $\mathrm{Ca}(\mathrm{OH})_{2}$ dissolves more and reacts with $\mathrm{CO}_{2}$ to generate $\mathrm{CaCO}_{3}$. Therefore, the leaching of hardened cement paste may be correlated with the mass gradient of $\mathrm{Ca}(\mathrm{OH})_{2}$.

In Figures 8 and 9, the mass fraction of the main phases determined by quantitative analysis is actually a relative quantity, and the mass fraction of $\mathrm{Ca}(\mathrm{OH})_{2}, \mathrm{CaCO}_{3}$, and $\mathrm{SiO}_{2}$ are selected as variables. In order to facilitate the comparison with the change trend of mechanical indexes, 
the ratio of $\mathrm{CaCO}_{3}$ to $\mathrm{Ca}(\mathrm{OH})_{2}$ mass fraction was taken as the change quantity, and the change curve of this ratio was drawn, as shown in Figure 10. It can be seen from Figure 10(a) that the mass ratio of OPC samples does not change much in different ages and tends to increase, indicating that the relative content of $\mathrm{CaCO}_{3}$ increases, the leaching of calcium is more obvious, and the greater the water velocity is, the greater its influence on Ca ions erosion is. For the SMC sample, the changing trend was similar to that of OPC, but the water velocity had little effect on the leaching effect. According to Figure 10(b), the leaching of the OPC sample took place from the outside in, while the leaching difference between the inside and outside of SMC sample was not significant, which shows that the leaching of hardened cement paste is related to the changes in the relative quantity of $\mathrm{CaCO}_{3}$ and $\mathrm{Ca}(\mathrm{OH})_{2}$. The higher the relative content of $\mathrm{CaCO}_{3}$ is, the denser the hardened cement paste is, and the better its erosion resistance is. The erosion resistance of hardened cement paste is related to the mass gradient of $\mathrm{Ca}(\mathrm{OH})_{2}$. The smaller the gradient is, the better the erosion resistance is.

Compared with mechanical properties test and XRD phase analysis, Rietveld phase quantitative calculation shows that the conclusions of three analytical methods are consistent.

\section{Conclusions}

Using tap water as the leaching medium, the leaching tests of three different hardened cement pastes with flow velocities of $0 \mathrm{~mm} / \mathrm{s}, 2.8 \mathrm{~mm} / \mathrm{s}$, and $11.2 \mathrm{~mm} / \mathrm{s}$ were carried out. The flexural strength, phase composition, and mass fraction of the paste after leaching were tested and analyzed. The following conclusions were drawn:

(1) Within 90 days, the effect of flow rate on the leaching of hardened cement paste is not obvious.

(2) Tap water acts as the erosion medium at test flow rate. Before $28 \mathrm{~d}$, the leaching of OPC and SMC is not obvious, and the flexural strength increases gradually. After $28 \mathrm{~d}$, the leaching of OPC is higher than that of SMC, and the flexural strength of OPC decreases, while the strength of SMC does not change much.

(3) XRD-Rietveld quantitative method was used to analyze the leaching characteristics of hardened cement paste. It is found that the leaching of hardened cement paste is related to the increase in $\mathrm{CaCO}_{3}$ content and the gradient of $\mathrm{Ca}(\mathrm{OH})_{2}$ content.

(4) By comparing the change in flexural strength and XRD diffraction intensity, the XRD-Rietveld method can be used to evaluate the leaching characteristics of hardened cement paste under flowing water.

\section{Data Availability}

The data used to support the findings of this study are available from the corresponding author upon request.

\section{Conflicts of Interest}

The authors declare that there are no conflicts of interest.

\section{Acknowledgments}

The research was funded by the National Key Research and Development Program of China (grant number 2017YFC0404902), Science and Technology Program of Water Resources Allocation Project in the Pearl River Delta (grant number 2020), University Natural Science Foundation of Education Department of Anhui Province (grant number KJ2017A725), Postgraduate Research \& Practice Innovation Program of Jiangsu Province (grant number KYCX17_0473), National Natural Science Foundation of China (grant number 51479048), and Fundamental Research Funds for the Central Universities (grant number 2017B701X14).

\section{References}

[1] E. Rozière and A. Loukili, "Performance-based assessment of concrete resistance to leaching," Cement and Concrete Composites, vol. 33, no. 4, pp. 451-456, 2011.

[2] Y.-B. Zhang, J.-N. Chen, G. V. Matthew et al., Effect of pH and Grain Size on the Leaching Mechanism of Elements from Recycled Concrete Aggregate, Springer-Verlag Singapore Pte Ltd, Singapore, Asia, 2018.

[3] M. C. Alonso, J. L. García Calvo, J. Cuevas et al., "Interaction processes at the concrete-bentonite interface after 13 years of FEBEX-plug operation. part I: concrete alteration," Physics and Chemistry of the Earth, Parts $A / B / C$, vol. 99, pp. 38-48, 2017.

[4] Y. Jia, H. B. Bian, S. Y. Xie, N. Burlion, and J. F. Shao, "A numerical study of mechanical behavior of a cement paste under mechanical loading and chemical leaching," International Journal for Numerical and Analytical Methods in Geomechanics, vol. 41, no. 18, pp. 1848-1869, 2017.

[5] I. Arribas, I. Vegas, V. García, R. Vigil De La Villa, S. Martínez-Ramírez, and M. Frías, "The deterioration and environmental impact of binary cements containing thermally activated coal mining waste due to calcium leaching," Journal of Cleaner Production, vol. 183, pp. 887-897, 2018.

[6] J. Jain and N. Neithalath, "Analysis of calcium leaching behavior of plain and modified cement pastes in pure water," Cement and Concrete Composites, vol. 31, no. 3, pp. 176-185, 2009.

[7] X. Wang, K. Xu, Y. Li, and S. Guo, "Dissolution and leaching mechanisms of calcium ions in cement based materials," Construction and Building Materials, vol. 180, no. 10, pp. 103-108, 2018.

[8] C. Vernet, C. Alonso, C. Andrade, M. Castellote, I. Llorente, and A. Hidalgo, "A new leaching test based in a Running water system to evaluate long-term water resistance of concretes," Advances in Cement Research, vol. 14, no. 4, pp. 157-168, 2002.

[9] Q. T. Phung, N. Maes, D. Jacques, G. De Schutter, and G. Ye, "Investigation of the changes in microstructure and transport properties of leached cement pastes accounting for mix composition," Cement and Concrete Research, vol. 79, pp. 217-234, 2016.

[10] H. Saito and A. Deguchi, "Leaching tests on different mortars using accelerated electrochemical method," Cement and Concrete Research, vol. 30, no. 11, pp. 1815-1825, 2000. 
[11] M. Jebli, F. Jamin, E. Garcia-Diaz, M. El Omari, and M. S. El Youssoufi, "Influence of leaching on the local mechanical properties of an aggregate-cement paste composite," Cement and Concrete Composites, vol. 73, pp. 241-250, 2016.

[12] F. Adenot and M. Buil, "Modelling of the corrosion of the cement paste by deionized water," Cement and Concrete Research, vol. 22, no. 2-3, pp. 489-496, 1992.

[13] Y. Yu and Y. X. Zhang, "Coupling of chemical kinetics and thermodynamics for simulations of leaching of cement paste in ammonium nitrate solution," Cement and Concrete Research, vol. 95, pp. 95-107, 2017.

[14] S. Hiroshi and N. Sunao, "Comparison between diffusion test and electromechanical acceleration test for leaching degradation of cement hydration products," ACI Materials Journal, vol. 96, no. 2, pp. 208-213, 1999.

[15] W. Lin, A. Cheng, R. Huang, C. Chen, and X. Zhou, "Effect of calcium leaching on the properties of cement-based composites," Journal of Wuhan University of Technology-Materials Science Ed.vol. 26, no. 5, pp. 990-997, 2011.

[16] L. G. Magdalena, R. Marcello, M. Paola, M. Cannio, and A. F. Gualtieri, "Full quantitative phase analysis of hydrated lime using the rietveld method," Cement and Concrete Research, vol. 42, no. 9, pp. 1273-1279, 2012.

[17] M. A. G. Aranda, A. G. De La Torre, and L. Ledn-Reirta, "5. Rietveld quantitative phase Analysis of OPC clinkers, cements and hydration products," Applied Mineralogy of Cement \& Concrete, vol. 74, no. 1, pp. 169-210, 2012.

[18] Y. Liu, S. Lei, Y. Li, F. Xie, and B. Li, "Influence of replacement level of coal-series kaolin on hydration of ordinary Portland cement by X-ray diffraction/rietveld method," Journal of Wuhan University of Technology-Materials Science Ed.vol. 34, no. 3, pp. 614-621, 2019.

[19] F. Cao and P. Yan, "The influence of the hydration procedure of $\mathrm{MgO}$ expansive agent on the expansive behavior of shrinkage-compensating mortar," Construction and Building Materials, vol. 202, pp. 162-168, 2019.

[20] N. K. Dhapekar and D. M. Chopkar, "Structural health monitoring of ordinary Portland cement concrete structures using X-ray diffraction," International Journal of Applied Engineering Research, vol. 11, no. 9, pp. 6128-6131, 2016.

[21] Y. Wei, W. Yao, X. Xing, and M. Wu, "Quantitative evaluation of hydrated cement modified by silica fume using QXRD, 27Al MAS NMR, TG-DSC and selective dissolution techniques," Construction and Building Materials, vol. 36, pp. 925-932, 2012.

[22] Y. Q. Wei and W. Yao, "Quantitative characterization of hydration of cement pastes by rietveld phase analysis and thermoanalysis," Key Engineering Materials, vol. 539, pp. 19-24, 2013.

[23] H. -T Zhao, K.-D. Jiang, R. Yang, Y. Tang, and J. Liu, "Experimental and theoretical analysis on coupled effect of hydration, temperature and humidity in early-age cement-based materials," International Journal of Heat and Mass Transfer, vol. 146, 2020.

[24] J. Liu, Y. Li, P. Ouyang, and Y. Yang, "Hydration of the silica fume-Portland cement binary system at lower temperature," Construction and Building Materials, vol. 93, pp. 919-925, 2015.

[25] J. W. Bullard, H. M. Jennings, R. A. Livingston et al., "Mechanisms of cement hydration," Cement and Concrete Research, vol. 41, no. 12, pp. 1208-1223, 2011.

[26] J. Jain and N. Neithalath, "Physico-chemical changes in nanosilica and silica fume modified cement pastes in response to leaching," International Journal of Materials and Structural Integrity, vol. 3, no. 2/3, pp. 114-133, 2009.

[27] D. Harbec, A. Tagnit-Hamou, and F. Gitzhofer, "Waste-glass fume synthesized using plasma spheroidization technology: reactivity in cement pastes and mortars," Construction and Building Materials, vol. 107, pp. 272-286, 2016.

[28] L. -C. Zhang and J. -K. Zhou, "Fractal characteristics of pore structure of hardened cement paste prepared by pressurized compact molding," Construction and Building Materials, vol. 259 , no. $1,2020$.

[29] N. B. Singh, M. Kalra, M. Kumar, and S. Rai, "Hydration of ternary cementitious system: Portland cement, fly ash and silica fume," Journal of Thermal Analysis and Calorimetry, vol. 119, no. 1, pp. 381-389, 2015.

[30] B. Uzal, L. Turanli, H. Yucel, M. C. Göncüoğlu, and A. Çulfaz, "Pozzolanic activity of clinoptilolite: a comparative study with silica fume, fly ash and a non-zeolitic natural pozzolan," Cement and Concrete Research, vol. 40, no. 3, pp. 398-404, 2010. 